\title{
BMJ Associations of metabolic factors and OPen adipokines with pain in incipient upper extremity soft tissue disorders: a cross-sectional study
}

\author{
Martti Rechardt, ${ }^{1,2}$ Rahman Shiri, ${ }^{1,2}$ Harri Lindholm, ${ }^{1}$ Jaro Karppinen, ${ }^{1,3}$ \\ Eira Viikari-Juntura ${ }^{2}$
}

To cite: Rechardt M, Shiri R, Lindholm $\mathrm{H}$, et al. Associations of metabolic factors and adipokines with pain in incipient upper extremity soft tissue disorders: a cross-sectional study. BMJ Open 2013;3: e003036. doi:10.1136/ bmjopen-2013-003036

- Prepublication history for this paper is available online. To view these files please visit the journal online (http://dx.doi.org/10.1136/ bmjopen-2013-003036).

Received 11 April 2013 Revised 11 June 2013 Accepted 1 July 2013

${ }^{1}$ Centre of Expertise for Health and Work Ability, Finnish Institute of Occupational Health, Helsinki, Finland

${ }^{2}$ Disability Prevention Centre, Finnish Institute of Occupational Health, Helsinki, Finland

${ }^{3}$ Institute of Clinical Medicine, Department of Physical and Rehabilitation Medicine, University of Oulu and Medical Research Center Oulu, Oulu, Finland

Correspondence to Dr Martti Rechardt; martti.rechardt@ttl.fi

\section{ABSTRACT}

Objectives: Earlier studies have suggested associations between metabolic factors and musculoskeletal pain or disorders. We studied the associations of obesity, lipids, other features of the metabolic syndrome and adipokines (adiponectin, leptin, resistin, visfatin) with upper extremity pain in a clinical population with incipient upper extremity soft tissue disorders (UESTDs).

Design: A cross-sectional study.

Setting: Primary healthcare (occupational health service) with further examinations at a research institute.

Participants: Patients ( $\mathrm{N}=163,86 \%$ were women) seeking medical advice in the occupational health service due to incipient upper extremity symptoms with symptom duration of $<1$ month were referred for consultation to the Finnish Institute of Occupational Health from Spring 2006 to Fall 2008. We included all actively working subjects meeting diagnostic criteria based on physical examination. We excluded subjects meeting predetermined conditions.

Outcome measure: Pain intensity was assessed with visual analogue scale and dichotomised at the highest tertile (cut-point 60).

Results: Obesity (adjusted OR for high waist circumference $2.9,95 \% \mathrm{Cl} 1.1$ to 7.3 ), high-density lipoprotein cholesterol (OR 3.9, 95\% Cl 1.4 to 10.1 for low level) and triglycerides (OR 2.6, $95 \% \mathrm{Cl} 1.0$ to 6.8 for high level) were associated with pain intensity. Of four adipokines studied, only visfatin was associated with upper extremity pain (adjusted OR 1.4, 95\% Cl 1.0 to 2.1 for 1SD increase in level).

Conclusions: Abdominal obesity and lipids may have an impact on pain intensity in UESTDs. They may intensify pain through proinflammatory pain-modifying molecular pathways or by causing soft tissue pathology and dysfunction of their supplying arteries. Of four adipokines studied only one (visfatin) was associated with pain intensity. In the future, further studies are required to better understand the relationship between metabolic factors and UESTDs.

\section{INTRODUCTION}

Upper extremity pain is a common health problem in general populations. The prevalence of forearm pain during the preceding

\section{ARTICLE SUMMARY}

\section{Article focus}

- We studied the associations of metabolic factors, serum C-reactive protein and adipokines with upper extremity pain intensity among subjects with incipient upper extremity soft tissue disorders (UESTDs).

\section{Key messages}

- Subjects with abdominal obesity, low level of high-density lipoprotein (HDL) cholesterol, high level of triglycerides or high level of the adipokine visfatin reported higher upper extremity pain intensity than those with normal waist circumference, higher level of HDL cholesterol, normal level of triglycerides, or low level of visfatin.

- Further studies are needed to understand the role of metabolic factors in UESTDs.

Strengths and limitations of this study

- Strengths of the study include: 1) Metabolic factors and adipokines were measured, and 2) Patients with early stage of upper extremity soft tissue disorders were included in the study.

- Limitations of the study include: 1) Small sample size, and 2) Cross sectional design of the study.

30 days has been estimated at $8 \%,{ }^{1}$ and that of shoulder pain has ranged between 12\% and $30 \% \cdot{ }^{1-4}$ In the general population, one of five persons reports chronic upper extremity pain. ${ }^{5}$ Common causes for upper extremity pain include soft tissue disorders, such as rotator cuff tendinitis, epicondylitis and tenosynovitis. ${ }^{6}$

Some studies have suggested an association between musculoskeletal pain or disorders and metabolic factors, such as obesity, lipids and hyperglycaemia. ${ }^{7-9}$ In a French working population study, men who are obese and women with diabetes had a significantly higher occurrence of upper extremity soft tissue disorders (UESTDs, mostly comprising tendon disorders) compared with subjects without such 
metabolic disorders. ${ }^{10}$ In addition, an association has been reported between carpal tunnel syndrome and serum lipids. ${ }^{11} 12$

Obesity is often an underlying factor for dyslipidaemia and disturbances of glucose metabolism. It may cause a systemic low-grade inflammation and increased proinflammatory activity with elevated cytokine levels. ${ }^{13}$ Dyslipidaemia may cause accumulation of lipids on musculoskeletal structures, for example, tendons. ${ }^{11}{ }^{12}$ Advanced glycation end-products may accumulate in hyperglycaemia resulting in latent collagen and microvascular alterations. ${ }^{13} 14$

Adipokines are proteins largely released by adipocytes, typically showing increased production in obesity. Characteristically, they exert widespread effects on immunological processes, for example, by stimulating cytokine expression. Adipokines function also in musculoskeletal disorders, best documented in degenerative inflammatory joint conditions. ${ }^{15}$ We are not aware of studies on the role of adipokines in non-inflammatory upper extremity disorders.

We studied the associations of obesity, lipids, other features of the metabolic syndrome and adipokines with upper extremity pain in a clinical population with incipient UESTDs.

We hypothesised that UESTD patients with obesity, dyslipidaemia, high $\mathrm{C}$ reactive protein (CRP) and adipokines report higher levels of pain intensity than patients without these risk factors. Furthermore, we explored whether the associations of adipokines with upper extremity pain differ in overweight and non-overweight subjects.

\section{METHODS}

\section{Patients}

This cross-sectional study was a part of a larger project on metabolic and inflammatory factors in UESTDs. Included conditions were shoulder disorders, for example, rotator cuff tendinitis, elbow disorders, for example, humeral epicondylitis and wrist disorders, for example, tenosynovitis. Between Spring 2006 and Fall 2008, three occupational healthcare units in Helsinki referred all eligible patients seeking medical advice for incipient upper extremity pain with symptom duration of less than 1 month to the Finnish Institute of Occupational Health for further examinations. In the final study population we included all actively working subjects meeting diagnostic criteria based on physical examination. ${ }^{16}$

We excluded patients whose main problem was a spine or cervical disorder, advanced osteoarthritis, autoimmune disease, fibromyalgia, malignancy, history of recent injury, former surgery related to the current problem and presence of deformity. We also excluded subjects with work absence for 2 weeks or longer prior to the medical examination, those needing sick leave immediately after the examination and those with three or more pain episodes of the same disorder during the previous year.

\section{Ethics statement}

The Coordinating Ethical Committee of Helsinki University Hospital District has approved this study on 16 of August 2006. All subjects signed an informed consent form before entering the study.

\section{Outcome}

Symptoms were determined by the examining physician. A standardised protocol was used that included symptom questions and clinical tests. A visual analogue scale was used to assess pain intensity during the preceding week $(0=$ no pain, $100=$ highest pain intensity possible). Pain intensity was dichotomised at the highest tertile (cut-off point 60).

\section{Independent variables}

We measured body height and weight, and systolic and diastolic blood pressure with standard procedures. Waist circumference was measured halfway between the lowest rib and iliac crest, and hip circumference was measured at the trochanter level. We calculated body mass index (BMI) as body weight (in kilograms)/height (in meters). ${ }^{2}$ The subjects were categorised according to BMI into underweight $(\mathrm{BMI}<18.5)$, normal weight (BMI 18.5-24.9), overweight (BMI 25.0-29.9) and obese (BMI $>30.0) .{ }^{17}$ Waist circumference was grouped into three levels: in men <94.0, 94.0-101.9 and $>102.0 \mathrm{~cm}$ and in women $<80.0,80.0-87.9$ and $>88.0 \mathrm{~cm}$. ${ }^{17}$ Waist-to-hip ratio was calculated as a ratio of waist circumference and hip circumference and classified into three groups: in men $<0.9,0.9-1.0$ and $>1.0$ and in women $<0.8,0.8-0.9$ and $>0.9 .{ }^{17}{ }^{18}$ Body fat was measured with the whole body bioimpedance technique (InBody 720, South Korea). We calculated body fat index as total body fat mass (in kilograms)/height (in meters). ${ }^{2}$ In addition, we inquired the use of regular drug treatment.

Fasting blood samples were analysed with Advia 1800 (Siemens Healthcare Diagnostics, USA) for serum total cholesterol, high-density lipoprotein (HDL) cholesterol, low-density lipoprotein (LDL) cholesterol, triglycerides and blood glucose as well as serum CRP. For lipids we applied clinical cut-off points recommended by the National Cholesterol Education Programme (NCEP) of the National Institutes of Health. ${ }^{19}$ We stratified lipid variables in tertiles in case the NCEP cut-off points resulted in too small subgroups. Fasting glucose was stratified in tertiles. To identify the metabolic syndrome we used the revised NCEP classification, ${ }^{20}$ requiring at least three of the following findings: (1) central obesity, defined as waist circumference $\geq 102 \mathrm{~cm}$ in men and $\geq 88 \mathrm{~cm}$ in women; (2) high fasting triglycerides, defined as $>1.7 \mathrm{mmol} / \mathrm{L}(>150 \mathrm{mg} / \mathrm{dL})$ or drug treatment for elevated triglycerides; (3) low HDL cholesterol defined as $<1.0 \mathrm{mmol} / \mathrm{L}$ in men $(<40 \mathrm{mg} / \mathrm{dL})$ and $<1.3 \mathrm{mmol} / \mathrm{L}$ $(<50 \mathrm{mg} / \mathrm{dL})$ in women or drug treatment for reduced 
HDL; (4) elevated blood pressure, defined as systolic blood pressure $\geq 130 \mathrm{~mm} \mathrm{Hg}$ or diastolic blood pressure $>85 \mathrm{~mm} \mathrm{Hg}$ or antihypertensive drug treatment with a history of hypertension; and (5) impaired fasting glucose, defined as fasting glucose $\geq 5.6 \mathrm{mmol} / \mathrm{L}$ $(100 \mathrm{mg} / \mathrm{dL})$ or drug treatment for elevated glucose.

High CRP was defined as $\geq 3.0 \mathrm{mg} / \mathrm{L} .^{21}$ Serum leptin, adiponectin, resistin (DuoSet ELISA R\&D systems) and visfatin (Human Visfatin ELISA Kit, AdipoGen) were determined with ELISA kits according to the manufacturer's instructions. Adipokines were used as continuous variables and their associations were modelled for 1SD increase in their level.

Smoking was classified as never, former, occasional or current. Alcohol consumption was determined as frequency of drinking alcohol per time unit, categorised into none or $\leq 1$ time/month, $2-4$ times/month or $\geq 2$ times/ week. Physical exercise was defined as the number of sessions per week of physical activities for at least $30 \mathrm{~min}$ causing sweating or shortness of breath and categorised into none or sometimes, 1-2, 3-4 or $\geq 5$ times/week.

Exposure to physical load factors was assessed with an interview by a physician. The patients were enquired about the frequency of heavy lifting, duration of working with hand above shoulder level, prolonged forceful gripping, as well as pinch grip that either required exertion or deviated wrist posture, and the use of vibrating tools. Each factor was dichotomised using a cut-off point of being exposed for $\geq 10 \%$ of the work time during a workday.

We assessed fear-avoidance beliefs with the 4-item Physical Activity Subscale of the Fear-Avoidance Beliefs Questionnaire $^{22}$ : 'physical activity makes my symptoms worse'; 'if my symptoms become worse, it means that I should stop what I was doing'; 'my pain is caused by work'; and 'I should not continue in my present job because of the symptoms'. Each item had a 7-point scale from 'totally disagree' to 'totally agree'. We defined fearavoidance beliefs as high when the score was $\geq 18$ (of maximum of 24).

We evaluated job strain using the ' 14 item' Job Content Questionnaire ( 5 for job demands and 9 for job control), ${ }^{23}$ each item being assessed with a 5-point scale ranging from 'strongly agree' to 'strongly disagree'. We dichotomised job demand and job control at the median to generate a job strain variable, high demand and low control signifying high job strain.

We used the PHQ-9 questionnaire to assess depressive symptoms. ${ }^{24}$ It consists of nine items with a 4-point scale (0-3), ranging from 0 to 27 . We defined mild to severe depressive symptoms according to the recommended cut-off value of $\geq 5$.

\section{Statistical analysis}

We dichotomised pain intensity at the highest tertile. We ran logistic regression models to study the associations of metabolic factors and adipokines with pain intensity controlling for age and gender. Because of small sample size, we first ran age-adjusted and gender-adjusted regression analyses to identify significant covariates within each family of independent variables. We grouped the independent variables into six families and ran six age- and gender-adjusted regression analyses for (1) weight-related factors (BMI, waist circumference and waist-hip ratio); (2) lipids (total cholesterol, LDL cholesterol, HDL cholesterol, HDL ratio and triglycerides); (3) other metabolic factors (fasting glucose, systolic and diastolic blood pressure and metabolic syndrome); (4) adipokines; (5) other lifestyle factors (smoking, alcohol consumption and physical exercise) and (6) workrelated factors (physical load and job strain). We looked at a possible confounding effect of depressive symptoms with further adjustment in the final models. Stratified analyses were carried out to assess whether the effects of adipokines differed between overweight and nonoverweight subjects. We used SPSS Statistics V.20.0 software for the analysis.

\section{RESULTS}

\section{Population characteristics}

The subjects were on average 45 years old and predominantly female (table 1). Fourteen per cent were obese using BMI as an indicator and $10 \%$ had high LDL cholesterol $(>4.1 \mathrm{mmol} / \mathrm{L})$. Thirty per cent had fasting glucose $\geq 5.6 \mathrm{mmol} / \mathrm{L}$ and $3 \% \geq 7.0 \mathrm{mmol} / \mathrm{L}$. Depressive symptoms were reported by $27 \%$ of the patients. Statin treatment was reported by $6 \%$ and antihypertensive medication by $15 \%$. None of the patients used fibrate or nicotinic acid treatment. About half (52\%) of the patients reported having used painkillers for their upper extremity problem, most of them irregularly. The mean pain intensity was 48 . The cut-off point for the highest tertile of pain intensity was 60. Subjects with shoulder disorders and epicondylitis each comprised about one-third of the study population, and those with nonspecific pain one-fifth.

\section{Metabolic factors and upper extremity pain}

Obesity was associated with pain intensity (table 2). The association was stronger with waist circumference or waist-to-hip ratio than with BMI. Subjects with low HDL cholesterol, high HDL ratio or high triglyceride levels reported high levels of pain intensity. Those with high job strain reported low pain intensity. The inverse association was partly explained by low waist circumference in those with high job strain (two-tailed independent samples t-test $\mathrm{p}=0.007)$. However, the association between job strain and pain intensity remained statistically significant after further adjustment for waist circumference. OR of pain intensity for high job strain was 0.3 (0.1-0.9) after adjustment for age, gender and waist circumference.

Fasting glucose, CRP, blood pressure, metabolic syndrome, leisure time physical exercise, smoking, alcohol 
Table 1 Characteristics of the study population ( $\mathrm{N}=163)$, percentage (\%) or mean (SD)

\begin{tabular}{|c|c|c|c|}
\hline Characteristic & $\%$ & Mean & SD \\
\hline Age (years) & & 45.0 & 9.8 \\
\hline Males & 14 & & \\
\hline Body mass index $\left(\mathrm{kg} / \mathrm{m}^{2}\right)$ & & 25.5 & 4.3 \\
\hline Waist circumference (cm) & & 83.4 & 12.7 \\
\hline Waist-to-hip ratio & & 0.83 & 0.08 \\
\hline Fat percent & & 27.2 & 8.0 \\
\hline Body fat index $\left(\mathrm{kg} / \mathrm{m}^{2}\right)$ & & 6.6 & 3.9 \\
\hline Total cholesterol (mmol/L) & & 5.1 & 0.9 \\
\hline LDL cholesterol (mmol/L) & & 2.9 & 0.8 \\
\hline HDL cholesterol (mmol/L) & & 1.7 & 0.5 \\
\hline Triglycerides (mmol/L) & & 1.1 & 0.6 \\
\hline Fasting glucose (mmol/L) & & 5.3 & 0.9 \\
\hline High CRP $(\geq 3.0 \mathrm{mg} / \mathrm{mL})$ & 18 & & \\
\hline Systolic blood pressure $(\mathrm{mm} \mathrm{Hg})$ & & 124 & 17 \\
\hline Diastolic blood pressure $(\mathrm{mm} \mathrm{Hg})$ & & 82 & 11 \\
\hline \multicolumn{4}{|l|}{ Adipokines } \\
\hline Adiponectin (pg/L) & & 3444 & 1553 \\
\hline Leptin (pg/L) & & 14762 & 12375 \\
\hline Resistin (pg/L) & & 14662 & 4481 \\
\hline Visfatin (ng/L) & & 1.1 & 0.6 \\
\hline Metabolic syndrome & 18 & & \\
\hline Current smoking & 11 & & \\
\hline $\begin{array}{l}\text { Alcohol consumption } \geq 2 \text { times per } \\
\text { week }\end{array}$ & 19 & & \\
\hline $\begin{array}{l}\text { Physical exercise } \geq 3 \text { times per } \\
\text { week }\end{array}$ & 51 & & \\
\hline High physical load & 37 & & \\
\hline High fear avoidance beliefs score & 13 & & \\
\hline High job strain & 26 & & \\
\hline Depressive symptoms & 27 & & \\
\hline \multicolumn{4}{|l|}{ Medication } \\
\hline Statin & 6 & & \\
\hline Antihypertensive & 15 & & \\
\hline Antidiabetic & 1 & & \\
\hline Antidepressive & 4 & & \\
\hline Pain intensity $(0-100)$ & & 48 & 22 \\
\hline \multicolumn{4}{|l|}{ Diagnostic subgroups } \\
\hline Shoulder disorder & 36 & & \\
\hline Epicondylitis & 31 & & \\
\hline $\begin{array}{l}\text { Wrist tendinitis or carpal tunnel } \\
\text { syndrome }\end{array}$ & 13 & & \\
\hline Non-specific pain & 20 & & \\
\hline
\end{tabular}

consumption, fear avoidance beliefs and physical work load factors showed no associations with pain intensity.

Within weight-related factors waist circumference, within lipids HDL and triglycerides, within adipokines visfatin and within the group of work-related factors job strain remained statistically significant in the family-wise analyses. In the final models, OR of upper extremity pain was 3.2 (95\% CI 1.3 to 7.9 ) for abdominal obesity, 4.1 (95\% CI 1.5 to 11.0 ) for low HDL cholesterol, 3.0 (95\% CI 1.2 to 7.6 ) for high triglycerides and 1.5 (95\% CI 1.0 to 2.1) for 1SD increment of visfatin (table 3). Further adjustment for depressive symptoms reduced the effects of abdominal obesity and triglycerides on pain intensity.
Table 2 Age and gender adjusted OR of pain intensity according to metabolic factors, adipokines, medication, depressive symptoms and work-related factors

\begin{tabular}{|c|c|c|}
\hline Characteristic & OR & $95 \% \mathrm{Cl}$ \\
\hline \multicolumn{3}{|c|}{ Body mass index $\left(\mathrm{kg} / \mathrm{m}^{2}\right)$} \\
\hline$<25.0$ & 1 & \\
\hline $25.0-29.9$ & 1.9 & 0.9 to 4 \\
\hline$\geq 30.0$ & 2.1 & 0.8 to 5. \\
\hline \multicolumn{3}{|c|}{ Waist circumference* } \\
\hline Normal & 1 & \\
\hline Overweight & 1.6 & 0.6 to 3 \\
\hline Obese & 3.2 & 1.4 to 7 \\
\hline \multicolumn{3}{|l|}{ Waist-hip ratio $†$} \\
\hline Normal & 1 & \\
\hline Overweight & 1.0 & 0.5 to 2 \\
\hline Obese & 3.3 & 1.3 to 8 \\
\hline \multicolumn{3}{|c|}{ Fat percent tertile } \\
\hline$<23.3$ & 1 & \\
\hline $23.3-30.5$ & 0.9 & 0.3 to 2 \\
\hline$>30.5$ & 1.7 & 0.7 to 4 . \\
\hline \multicolumn{3}{|c|}{ Body fat index tertile $\left(\mathrm{kg} / \mathrm{m}^{2}\right)$} \\
\hline$<5.13$ & 1 & \\
\hline $5.13-7.41$ & 0.9 & 0.4 to 2 . \\
\hline$>7.41$ & 1.6 & 0.7 to 3. \\
\hline
\end{tabular}

Total cholesterol tertile $(\mathrm{mmol} / \mathrm{L})$ $<4.7$ $4.7-5.3$

0.4 to 2.7 $>5.3$ 0.8 to 4.0

LDL cholesterol tertile $(\mathrm{mmol} / \mathrm{L})$ $<2.5$ $2.5-3.3$

0.4 to 2.6 $>3.3$ 0.7 to 4.2

$\mathrm{HDL}$ cholesterol tertile $(\mathrm{mmol} / \mathrm{L})$ $>1.83$

$1.48-1.83$

0.4 to 2.2 $<1.48$ 1.2 to 6.3

$\mathrm{HDL}$ ratio tertile $<2.73$ 2.73-3.31

1.2 to 6.9 $>3.31$

1.1 to 6.4

Triglycerides tertile $(\mathrm{mmol} / \mathrm{L})$ $<0.72$ $\begin{array}{ll}0.72-1.08 & 1.7\end{array}$ $\begin{array}{ll}0.72-1.08 & 2.8\end{array}$

0.7 to 4.0 1.2 to 6.6

Adipokinesł Adiponectin $\quad 0.9 \quad 0.6$ to 1.3 Leptin $\quad 1.2$ Resistin $\quad 1.2$ Visfatin $\quad 1.4$ 0.9 to 1.8

0.8 to 1.6 1.0 to 2.0

Medication

Statin

0.9

Antihypertensive $\quad 1.5$

0.2 to 4.3

Antidepressive

0.6 to 3.8

0.2 to 7.6

Depressive symptoms

1.2 to 5.2

Physical load

0.7 to 3.1

Job strain

0.1 to 0.7

Fear avoidance beliefs

0.4 to 3.4

*Normal: men $<94 \mathrm{~cm}$, women $<80 \mathrm{~cm}$; overweight: men 94-101.9 cm, women $80-87.9 \mathrm{~cm}$; obese: men $\geq 102 \mathrm{~cm}$, women $\geq 88 \mathrm{~cm}$. †Normal: men $<0.9$, women $<0.8$; Overweight: men 0.9-1.0; obese: women $0.8-0.9$ men $>1.0$; women $>0.9$. $\ddagger$ Continuous variable; increment of $1 \mathrm{SD}$. 
Table 3 The associations of obesity, lipids and adipokines with upper extremity pain intensity

\begin{tabular}{|c|c|c|c|c|}
\hline & OR $^{*}$ & $95 \% \mathrm{Cl}$ & OR† & $95 \% \mathrm{Cl}$ \\
\hline \multicolumn{5}{|c|}{ Waist circumference $\ddagger$} \\
\hline Normal & 1 & & 1 & \\
\hline Overweight & 1.2 & 0.5 to 3.2 & 1.2 & 0.4 to 3.2 \\
\hline Obese & 3.2 & 1.3 to 7.9 & 2.9 & 1.1 to 7.3 \\
\hline \multicolumn{5}{|c|}{ HDL cholesterol tertile (mmol/L) } \\
\hline$>1.83$ & 1 & & 1 & \\
\hline $1.48-1.83$ & 0.8 & 0.3 to 2.2 & 0.7 & 0.2 to 2.0 \\
\hline$<1.48$ & 4.1 & 1.5 to 11.0 & 3.9 & 1.4 to 10.1 \\
\hline \multicolumn{5}{|c|}{ Triglycerides tertile (mmol/L) } \\
\hline$<0.72$ & 1 & & 1 & \\
\hline $0.72-1.08$ & 1.6 & 0.6 to 4.1 & 1.4 & 0.5 to 3.8 \\
\hline$>1.08$ & 3.0 & 1.2 to 7.6 & 2.6 & 1.0 to 6.8 \\
\hline Visfatin§ & 1.5 & 1.0 to 2.1 & 1.4 & 1.0 to 2.1 \\
\hline \multicolumn{5}{|c|}{$\begin{array}{l}\text { *Adjusted for age, gender, statin medication, alcohol consumption } \\
\text { and job strain. } \\
\text { †Further adjustment for depressive symptoms. } \\
\ddagger \text { Normal: men }<94 \mathrm{~cm} \text {, women }<80 \mathrm{~cm} \text {; overweight: men } 94- \\
101.9 \mathrm{~cm} \text {, women } 80-87.9 \mathrm{~cm} \text {; obese: men } \geq 102 \mathrm{~cm} \text {, women } \\
\geq 88 \mathrm{~cm} \text {. } \\
\text { §Continuous variable; increment of } 1 \mathrm{SD} \text {. }\end{array}$} \\
\hline
\end{tabular}

Waist circumference remained statistically significant with HDL in the model (OR 2.6, 95\% CI 1.0 to 6.9 for abdominal obesity) but not when triglycerides were included in the model (OR 2.4, 95\% CI 0.8 to 6.9). With waist circumference in the final model, OR was 3.2 (95\% CI 1.1 to 9.0) for low HDL cholesterol and 2.3 (95\% CI 0.8 to 6.8 ) for high triglycerides. The association between visfatin and upper extremity pain was similar in overweight and non-overweight subjects. OR of pain intensity for visfatin was 1.8 (95\% CI 0.6 to 5.1 ) among non-overweight subjects and 2.0 (95\% CI 0.8 to 4.6) among overweight/obese subjects.

In a subanalysis including women not on statin or antihypertensive medication and adjusting for age, alcohol consumption and job strain, pain intensity was associated with obesity (OR 2.8, 95\% CI 1.0 to 7.6), HDL cholesterol (OR 4.3, 95\% CI 1.5 to 12.5 for low level), triglycerides (OR 2.6, 95\% CI 1.0 to 7.0 for high level) and visfatin (OR 1.8, 95\% CI 1.1 to 2.7 for 1SD increase in level). With waist circumference in the final model, OR was 3.9 (95\% CI 1.3 to 11.8 ) for low HDL cholesterol, $2.0(95 \%$ CI 0.7 to 6.3$)$ for high triglycerides and 1.6 (95\% CI 1.0 to 2.5$)$ for visfatin.

\section{DISCUSSION}

Our study suggests independent associations of abdominal obesity and HDL with upper extremity pain in an inception cohort of patients with non-inflammatory upper extremity disorders. Moreover, of four studied adipokines (leptin, adiponectin, resistin, visfatin) only one (visfatin) was associated with upper extremity pain. Our findings support the role of abdominal obesity in upper extremity pain. Of obesity-related indictors we looked at lipids, measures of glucose metabolism, a non-specific marker of inflammation and adipokines; however, our results did not clearly indicate any specific pathomechanical pathway.

We studied three commonly occurring specific softtissue disorders of the upper extremity: shoulder disorders (most typically shoulder tendinitis or shoulder impingement syndrome), epicondylitis and tenosynovitis of the wrist. Previous studies have found associations between metabolic factors and these disorders. ${ }^{9} 10$ Metabolic factors, such as obesity and lipids, have been associated also with carpal tunnel syndrome. ${ }^{11} 12$ Moreover, carpal tunnel syndrome may be a result of wrist flexor tenosynovitis.

The associations of weight-related factors-especially abdominal obesity measured with waist circumferencepoint to a possible pain modulating role of abdominal fat in the early stage of UESTDs. Body fat indicators of body composition did not show an association with upper extremity pain, probably because they do not measure abdominal obesity. The whole body bioimpedance technique is a valid method to estimate body fat percentage in normal or overweight subjects. In obese individuals (BMI >30) the accuracy is only moderate. ${ }^{25}$ Therefore, waist circumference, as a traditional method of assessing abdominal fat accumulation, can be recommended for studies of UESTDs.

Serum lipids were associated with upper extremity pain, suggesting that they may have an independent role in soft-tissue pain modification at an early stage of UESTDs. We used data-driven cut-off points to study the associations of HDL and triglycerides with pain, and the cut-off points were lower for triglycerides and higher for HDL cholesterol than the clinical cut-off points recommended by NCEP. Only the lowest tertile of HDL cholesterol and the highest tertile of triglycerides were associated with pain intensity.

Adjusting for depressive symptoms decreased slightly the associations of obesity and lipids with pain intensity. Depressive symptoms and obesity are associated and the association seems to be bidirectional. $^{26}$ Moreover, depressive symptoms may precede pain or they can be a consequence of pain. ${ }^{27}$ If depressive symptoms precede pain, not adjusting for depression will lead to an overestimation of the effects of obesity and lipids on pain. On the other hand, if depressive symptoms are a consequence of pain, adjustment for depression will lead to an underestimation of the effects of obesity and lipids on pain. Depressive people may have a higher perception of pain, ${ }^{29}$ which would also lead to an overestimation of these associations.

In agreement with our study, some former studies have suggested an association of HDL with musculoskeletal pain. ${ }^{31}$ Abdominal obesity, a major feature of the metabolic syndrome, is characteristically associated with systemic low-grade inflammation, as well as with both decreased HDL and increased triglycerides. ${ }^{12} \quad 32$ Increased synthesis of, for example, Interleukin-1 (IL-1), a pivotal proinflammatory cytokine, may be a mediator 
in the pathomechanical pathway to increased pain intensity in UESTDs. Moreover, HDL has been shown to be an antiatherogenic particle and an attenuator of vascular inflammation. ${ }^{33}$ Therefore, HDL might also function as a pain modulator owing to its anti-inflammatory properties. Furthermore, increased triglycerides may function as an immunological metabolic stress signal, modifying pain through consecutive proinflammatory cascades. ${ }^{34} 35$ Finally, all these metabolic factors are involved in the pathomechanism of endothelial dysfunction and subsequent atherosclerosis. ${ }^{12}$

Of the adipokines studied, a high level of circulating visfatin was linked with upper extremity pain. Previous studies of rheumatoid arthritis and osteoarthritis have shown resistin and visfatin expression linking with disease activity, ${ }^{36-38}$ suggesting indirectly a relationship between adipokines and pain in these conditions. Visfatin is a metabolically active insulin imitator secreted by white adipose tissue and expressed increasingly by fat accumulation. In contrast, in humans other cell types than adipocytes mostly synthesise resistin, such as mononuclear and endothelial cells, unrelated with fat mass. Both resistin and visfatin are proinflammatory stimulating, for example, IL-1 and IL-6 expression that have distinct effects on the musculoskeletal system. In osteoarthritis, for instance, cartilage damage signalling occurs partly by cytokines such as IL-6. In UESTDs, these proinflammatory proteins may participate also in pain signalling in cooperation with adipokines. Furthermore, adipokines and lipids may have parallel inflammatory pain signalling pathways in UESTDs.

The population of the current study was predominantly women due to the workplace settings in question such as a central hospital. Owing to the small number of men we could not run appropriate regression analyses to see whether the associations found among women were similar in men. Therefore, the findings of this study can be generalised to women only. Moreover, due to cross-sectional nature of the current study causal inference cannot be made.

In conclusion, obesity, especially abdominal obesity and lipids may have an impact on pain intensity in UESTDs. They may intensify pain through proinflammatory pain-modifying molecular pathways or by causing soft tissue pathology and dysfunction of their supplying arteries. Of four adipokines studied only one (visfatin) was associated with pain intensity. In the future, further studies are required to better understand the relationship between metabolic factors and UESTDs.

Contributors M R was involved in data acquisition, data analysis, interpretation and manuscript drafting. R S was involved in data analysis and interpretation and manuscript drafting. $\mathrm{H} \mathrm{L}$ was involved in data analysis and interpretation and critically revised the manuscript. J K was involved in conception and design of the study, data analysis and interpretation and critically revised the manuscript. E V-J was in charge of the conception and design of the study, and was involved in data analysis and interpretation and manuscript drafting. All authors approved the final manuscript.

Funding The Finnish Academy (project numbers 111061 and 129362) and the Finnish Work Environment Fund (project number 300910) granted the study.
Competing interests None.

Patient consent Obtained.

Ethics approval The Coordinating Ethical Committee of Helsinki University Hospital District.

Provenance and peer review Not commissioned; externally peer reviewed.

Data sharing statement No additional data are available.

Open Access This is an Open Access article distributed in accordance with the Creative Commons Attribution Non Commercial (CC BY-NC 3.0) license, which permits others to distribute, remix, adapt, build upon this work noncommercially, and license their derivative works on different terms, provided the original work is properly cited and the use is non-commercial. See: http:// creativecommons.org/licenses/by-nc/3.0/

\section{REFERENCES}

1. Palmer KT. Regional musculoskeletal conditions: pain in the forearm, wrist and hand. Best Pract Res 2003;17:113-35.

2. Luime JJ, Koes BW, Hendriksen IJ, et al. Prevalence and incidence of shoulder pain in the general population; a systematic review. Scand J Rheumatol 2004;33:73-81.

3. Miranda $\mathrm{H}$, Viikari-Juntura $\mathrm{E}$, Heistaro $\mathrm{S}$, et al. A population study on differences in the determinants of a specific shoulder disorder versus nonspecific shoulder pain without clinical findings. $A m \mathrm{~J}$ Epidemiol 2005;161:847-55.

4. Urwin M, Symmons D, Allison T, et al. Estimating the burden of musculoskeletal disorders in the community: the comparative prevalence of symptoms at different anatomical sites, and the relation to social deprivation. Ann Rheum Dis 1998;57:649-55.

5. Gummesson C, Atroshi I, Ekdahl C, et al. Chronic upper extremity pain and co-occurring symptoms in a general population. Arthritis Rheum 2003;49:697-702.

6. Shiri R, Varonen $\mathrm{H}$, Heliövaara $\mathrm{M}$, et al. Hand dominance in upper extremity musculoskeletal disorders. J Rheumatol 2007;34:1076-82.

7. Leino-Arjas $P$, Kauppila L, Kaila-Kangas L, et al. Serum lipids in relation to sciatica among Finns. Atherosclerosis 2008;197:43-9.

8. Mäntyselka $P$, Kautiainen $H$, Vanhala $M$. Prevalence of neck pain in subjects with metabolic syndrome-a cross-sectional population-based study. BMC Musculoskelet Disord 2010;11:171

9. Viikari-Juntura E, Shiri R, Solovieva S, et al. Risk factors of atherosclerosis and shoulder pain-is there an association? A systematic review. Eur J Pain 2008;12:412-26.

10. Roquelaure $\mathrm{Y}, \mathrm{Ha} \mathrm{C}$, Rouillon $\mathrm{C}$, et al. Risk factors for upper-extremity musculoskeletal disorders in the working population. Arthritis Rheum 2009;61:1425-34.

11. Gaida JE, Ashe MC, Bass SL, et al. Is adiposity an under-recognized risk factor for tendinopathy? A systematic review. Arthritis Rheum 2009;61:840-9.

12. Gustafson B. Adipose tissue, inflammation and atherosclerosis $J$ Atheroscler Thromb 2010;17:332-41.

13. Arkkila PE, Gautier JF. Musculoskeletal disorders in diabetes mellitus: an update. Best Pract Res 2003;17:945-70.

14. Lee HY, Oh BH. Aging and arterial stiffness. Circ J 2010;74:2257-62.

15. Lago F, Dieguez C, Gomez-Reino J, et al. Adipokines as emerging mediators of immune response and inflammation. Nat Clin Pract 2007:3:716-24.

16. Rechardt M, Shiri R, Matikainen S, et al. Soluble IL-1RII and IL-18 are associated with incipient upper extremity soft tissue disorders. Cytokine 2011;54:149-53.

17. WHO. Obesity: preventing and managing the global epidemic. Report of a WHO consultation. World Health Organization technical report series, 2000:i-xii, 1-253.

18. Croft JB, Keenan NL, Sheridan DP, et al. Waist-to-hip ratio in a biracial population: measurement, implications, and cautions for using guidelines to define high risk for cardiovascular disease. J Am Diet Assoc 1995;95:60-4.

19. National Institutes of Health. National Cholesterol Education Program. National Heart L, and Blood Institute. Detection, Evaluation, and Treatment of High Blood Cholesterol in Adults (Adult Treatment Panel III). NIH Publication, 2001; No. 01-3670 May 2001.

20. Grundy SM, Brewer HB Jr, Cleeman JI, et al. Definition of metabolic syndrome: report of the National Heart, Lung, and Blood Institute/ American Heart Association conference on scientific issues related to definition. Circulation 2004;109:433-8. 
21. Ridker PM, Hennekens $\mathrm{CH}$, Buring JE, et al. C-reactive protein and other markers of inflammation in the prediction of cardiovascular disease in women. N Engl J Med 2000;342:836-43.

22. Waddell G, Newton M, Henderson I, et al. A Fear-Avoidance Beliefs Questionnaire (FABQ) and the role of fear-avoidance beliefs in chronic low back pain and disability. Pain 1993:52:157-68.

23. Karasek R, Brisson C, Kawakami N, et al. The Job Content Questionnaire (JCQ): an instrument for internationally comparative assessments of psychosocial job characteristics. J Occup Health Psychol 1998;3:322-55.

24. Kroenke K, Spitzer RL, Williams JB. The PHQ-9: validity of a brief depression severity measure. J Gen Intern Med 2001;16:606-13.

25. Shafer KJ, Siders WA, Johnson LK, et al. Validity of segmental multiple-frequency bioelectrical impedance analysis to estimate body composition of adults across a range of body mass indexes. Nutrition (Burbank, Los Angeles County, CA) 2009;25:25-32.

26. Luppino FS, De Wit LM, Bouvy PF, et al. Overweight, obesity, and depression: a systematic review and meta-analysis of longitudinal studies. Arch Gen Psychiatry 2010;67:220-9.

27. Rouwette $\mathrm{T}$, Vanelderen $\mathrm{P}$, Reus MD, et al. Experimental neuropathy increases limbic forebrain CRF. Eur J Pain 2011;16:61-71.

28. Blackburn-Munro G, Blackburn-Munro RE. Chronic pain, chronic stress and depression: coincidence or consequence? $J$ Neuroendocrinol 2001;13:1009-23.

29. Cimmino MA, Ferrone C, Cutolo M. Epidemiology of chronic musculoskeletal pain. Best Pract Res 2011;25:173-83.
30. Spallone V, Morganti R, D'Amato C, et al. Clinical correlates of painful diabetic neuropathy and relationship of neuropathic pain with sensorimotor and autonomic nerve function. Eur $J$ Pain 2011;15:153-60.

31. Heuch I, Heuch I, Hagen K, et al. Associations between serum lipid levels and chronic low back pain. Epidemiology (Cambridge, MA) 2010;21:837-41.

32. Mottillo S, Filion KB, Genest $\mathrm{J}$, et al. The metabolic syndrome and cardiovascular risk a systematic review and meta-analysis. J Am Coll Cardiol 2010;56:1113-32.

33. Lowenstein CJ, Cameron SJ. High-density lipoprotein metabolism and endothelial function. Curr Opin Endocrinol Diabetes Obes 2010;17:166-70.

34. Hotamisligil GS. Inflammation and metabolic disorders. Nature 2006;444:860-7.

35. Martinon F. Detection of immune danger signals by NALP3. $J$ Leukocyte Biol 2008;83:507-11.

36. Rho YH, Solus J, Sokka T, et al. Adipocytokines are associated with radiographic joint damage in rheumatoid arthritis. Arthritis Rheum 2009;60:1906-14.

37. Krysiak R, Handzlik-Orlik G, Okopien B. The role of adipokines in connective tissue diseases. Eur J Nutr 2012;51:513-28.

38. Duan Y, Hao D, Li M, et al. Increased synovial fluid visfatin is positively linked to cartilage degradation biomarkers in osteoarthritis. Rheumatol Int 2012;32:985-90. 